\title{
cDNA cloning, Phylogenic Analysis and Gene Expression Pattern of Phenylalanine ammonia-lyase in Sugarcane (Saccharum officinarum L.)
}

\author{
Mahmoud Hashemitabar ${ }^{1}$, Maryam Kolahi' ${ }^{2}$ Mohammad Reza Tabandeh ${ }^{3 *}$, Parisa \\ Jonoubi $^{4}$ and Ahmad Majd ${ }^{4}$ \\ ${ }^{1}$ Cellular and Molecular Research Center; Faculty of Medicine; Ahvaz Jundishapour University of Medical \\ Sciences; Ahvaz - Iran. ${ }^{2}$ Department of Biology; Faculty of Science; ShahidChamran University of Ahvaz; Ahvaz - \\ Iran. ${ }^{3}$ Department of Biochemistry and Molecular Biology; Faculty of Veterinary Medicine; Shahid Chamran \\ University of Ahvaz; Ahvaz - Iran. ${ }^{4}$ Department of Plant Biology; Faculty of Biology Science; Kharazmi University; \\ Tehran - Iran
}

\begin{abstract}
The aim of the present study was to clone and characterize a full length cDNA of sugarcane (Saccharum officinarum) phenylalanine ammonia-lyase (SoPAL). Differential tissue expression pattern of the SoPAL transcript and its enzyme activity was also analyzed during the tillering stage of growth. The full-length of SoPAL cDNA was $2118 \mathrm{bp}$ long and contained a protein with 706 amino acids, determined by encoding technique. The amino acid sequence and phylogenic analysis of the cloned SoPAL showed high similarity to PAL from other monocotyledonous such as sorghum (96\%), maize (93\%) and Bamboos (87.12\%). The highest levels of SoPAL transcript were observed in the root and stem, while its minimal gene expression levels were in the leaves and sheath, respectively. The highest level of SoPAL enzyme activity was in the leaves. These results helped to understanding the characteristics of PAL biosynthesis and its regulation at the molecular level in sugarcane. This information could be critical for the manipulation of phenylpropanoid biosynthesis in the plant using biotechnological processes.
\end{abstract}

Key words: phenylalanine ammonia-lyase, Saccharum officinarum L, cloning, tissue expression

\section{INTRODUCTION}

Sugarcane (Saccharum officinarum L.) is a member of the Andropogoneae tribe of the Poaceae family and is one of the most important industrial plants in the world due to its high sucrose content (10 to $15 \%$ of stalk weight). It is considered as the main raw material in the sugar industry since $70 \%$ of the world's sugar comes from this plant (Guillermo et al. 1999). In addition to sugar, there are other beneficial byproducts such as bagasse with industrial and environmental importance produced by this plant. Sugarcane bagasse is a good low cost raw material for paper and animal feed due to its structural polymer, lignin rich in p-coumaryl subunits (Chiang et al. 1988; Leng et al. 1991). These products and other secondary metabolites, such as flavonoids, anthocyanins, lignins, UV protectants, phytoalexins and coumarins, are produced through the phenylpropanoid pathway. These metabolites are important for the normal growth of the plant and its response to different stress factors such as abiotic, biotic and high salt conditions (Logemann and Hahlbrock 1995; Jiang and Joyce 2003; Campos et al. 2005; Morelló et al. 2005; SureshIyer et al. 2010). Phenylalanine ammonia-lyase (PAL, EC 4.3.1.5) is the first rate limiting enzyme

*Author for correspondence: m.tabandeh @ scu.ac.ir 
of this pathway and catalyzes the non-oxidative deamination of phenylalanine to trans-cinnamic acid and ammonia (Hyun et al. 2001; Ferrer et al. 2008). Due to its central role in the phenylpropanoid pathway, PAL is one of the most extensively studied plant enzymes. It is encoded by a small gene family in the plants with four members in Arabidopsis (Huang et al. 2010). One exception is the potato PAL gene family, made up of 40- 50 genes and the loblolly pine PAL, which has been reported to be encoded by a single gene (Chang and Lim 2008). Using transgenic plants, it has been shown that PAL activity is a major control point for regulating the phenylpropanoid pathway (Shadlea et al. 2003) and modulating many secondary metabolites biosynthesis in the plants (Huang et al. 2010; Gao et al. 2012; Coulon et al. 2012).

It has been shown that PAL plays an important role in the defense against pathogen invasion by the biosynthesis of coumarin compound like scopoletin or precursors of lignin-like material. PAL is also a key enzyme involved in the biosynthesis of the signal molecule such as salicylic acid, which has been shown to accumulate in the cells undergoing hypersensitive response and to be essential for local and systemic resistance response (Boller 1995; Yang et al. 2012).

Characterization of the molecular structure and expression pattern of different genes in the plants can be utilized in modifying the metabolic pathways for biotechnological synthesis of new products or development of valuable agronomic traits in the plants. In recent years, many genes expressed in sugarcane tissues have been detected at translational and transcriptional levels by different methods (Leng et al. 1991). To-date, no published data are available about the nucleotide sequence and tissue expression of the PAL gene from sugarcane. The main goal of the current study was to clone and analyze the phylogenetic of the PAL cDNA from sugarcane. The study also for the first time is reporting tissue expression pattern of the PAL gene and its enzyme activity in different parts of the sugarcane.

\section{MATERIALS AND METHODS}

\section{Plant Material}

Samples of the commercial sugarcane (cultivar CP69-1062) were taken from 7-8 months old plants during the tillering stage. Plant materials were grown on a farm at the Sugarcane Research Center, Karun Agro-industrial Co., a region situated in the province of Khozestan (Ahvaz, Iran). The plants were taken in three replicates. Samples were taken from each plant: lamina, sheath from the last fully expanded leaf; stem from $7^{\text {th }}$ and $8^{\text {th }}$ internodes and roots. All the parts were chopped into small pieces, put in $50 \mathrm{~mL}$ polypropylene tubes, and immediately snap-frozen in liquid nitrogen.

\section{RNA preparation and reverse transcription}

Total RNA was extracted from the frozen samples by Trizol RNA isolation reagent (Life Technologies, USA) and stored at $80^{\circ} \mathrm{C}$. RNA was quantified at a wavelength of $260 \mathrm{~nm}$ by a nanodrop spectrophotometer (NanoDrop 2000 ${ }^{\mathrm{TM}}$, USA). The integrity of RNA was verified by OD 260/280 $\mathrm{nm}$ between 1.8 and 2.0. For genomic DNA removal, an in-solution DNase digestion was carried out by treating $1.0 \mu \mathrm{g}$ of RNA with two units of DNase I (Fermentas Inc, Vilnius, Lithuania).

\section{Reverse transcription-polymerase chain reaction}

Reverse transcription was done in a total volume of $20 \mu \mathrm{L}$ by using an AmpliSence cDNA synthesis kit (AmpliSens Enterovirus-Eph, Russia) as recommended by the manufacturer. PCRs were performed in a $25-\mu \mathrm{L}$ reaction using MaxTaq DNA polymerase Kit (Vivantis Technologies, Selangor DE, Malaysia) using a thermal cycler (Eppendorf Mastercycler Thermal Cycler, Hamburg, Germany). Specific sets of primers (BIONEER, Seoul, South Korea) used for the amplification of sugarcane PAL were as follows; forward: atggegggcaacggcgecat and reverse: ccatcaacgtcgtcaactaa. These primers were designed to amplify the PAL open reading frame based on the consensus sequences of the PAL ortolologs of maize, wheat, rice, bamboos, and barley using Beacon Designer 7.1. Thermal conditions for the amplification of PAL were 35 cycles consisting of denaturing at $94^{\circ} \mathrm{C}$ for $1 \mathrm{~min}$, annealing at $58^{\circ} \mathrm{C}$ for $1 \mathrm{~min}$, extension at $72^{\circ} \mathrm{C}$ for $1 \mathrm{~min}$, with an initial denaturing step at $95^{\circ} \mathrm{C}$ for $10 \mathrm{~min}$ and a final extension step at $72^{\circ} \mathrm{C}$ for 10 min. A reaction without cDNA was used as negative control. The PCR product was visualized by agarose gel electrophoresis (1\%). 


\section{PAL sequencing and analysis}

The PCR product of PAL cDNA was purified using the QIAquick Gel extraction Kit (Qiagen, Germany), cloned into the pTZ 57R/T Vector, using a Fermentase PCR cloning Kit (Fermentas Inc., Vilnius, Lithuania) and transformed into competent GM2163 E. coli using chilled calcium chloride as recommended previously (Hsieh et al. 2010). The Roche High Pure Plasmid Isolation kit was then used to purify the plasmid according to the manufacturer's instructions (Roche Applied Science, Germany). The plasmid was sequenced using M13 primers (Fermentas Inc., Vilnius, Lithuania) and Big Dye Terminator V.3.1 Cycle Sequencing kit in an ABI 3130 Genetic Analyzer (Applied Biosystems, USA).

\section{Phylogenetic analysis}

The DNA sequence of SoPAL was extracted using Vector NTI@ software (Life Technology, USA) and multiple sequence alignment between the PALs from sugarcane and various species of geramineae. This was performed using nBLAST (http://blast.ncbi.nlm.nih.gov/Blast.cgi) and Jalview 2.7 softwares. The amino acid sequence of the cloned SoPAL was deduced using ExPASy translate tool (http://expasy.org/tools/ pi_tool.html). Phylogenic trees were constructed based on amino acid sequences of the PALs from different species by using the neighbor joining method and Phylogeny.fr software. The topological stability of the trees was evaluated by 1,000 bootstrap replications.

\section{Quantitative real time PCR}

To evaluate the levels of PAL gene expression in different parts (root, stem, leaf, sheath) of the sugarcane, quantitative real-time PCR (qRT-PCR) was performed using the ABI Step One plus realtime PCR detection system (ABI plus; Applied Biosystems, USA), and $\mathrm{qPCR}^{\mathrm{TM}}$ Green master kit for SYBR Green I® (Applied Biosystems, USA). The relative expression level of PAL transcript was normalized to RNA loading for each sample using GAPDH mRNA as described previously (Schmittgen and Livak, 2008).

Sequences of sense and antisense primers (BIONEER, Seoul, South Korea) for SoPAL and ScGAPDH were designed by the Primer Express 3 software (ABI, USA) were as follows: SoPAL: 5'-TCTTGTGCGAGGTGATGAAC-3' and 3'-AAGCACGCCAAGAAGGTGAA-5' and for ScGAPDH: 5' - AGTTCAACGGCACAGTCAAG $-3^{\prime}$ and 5'-TACTCAGCACCAGCATCACC-3'. Real time PCR reactions were performed in a final volume of $15 \mu \mathrm{l}$ containing forward and reverse primers $(100 \mathrm{~nm})$, cDNA $(3.0 \mu \mathrm{L})$, water DNase free $(4.0 \mu \mathrm{L})$ and $2 \mathrm{x}$ Greenstar qPCR Master Mix $(7.5 \mu \mathrm{L})$. The reactions were performed with the following settings: predenaturation $\left(95^{\circ} \mathrm{C}, 5 \mathrm{~min}\right)$ followed by 40 cycles at $95^{\circ} \mathrm{C}, 30 \mathrm{sec}$ and $60^{\circ} \mathrm{C}$; $45 \mathrm{sec}$. Reactions were performed in duplicate. Reactions without cDNA were performed in parallel as negative controls. Step One software 2.1 was used for the analysis of qRT-PCR results, based on $\Delta \Delta \mathrm{Ct}$ method. Relative quantification was performed according to the comparative $2^{-\Delta \Delta \mathrm{Ct}}$ method as described previously (Schmittgen and Livak 2008). Validation of the assay to check that the primer for the housekeeping gene (GAPDH) and PAL had similar amplification efficiencies was performed as described previously (Rieu and Powers 2002).

\section{Assays of PAL enzyme activity}

PAL enzyme activity was measured as described previously by Copeland (Copeland 2000). Plant samples $(100 \mathrm{mg})$ were homogenized with a mortar and pestle in the extraction buffer containing $50 \mathrm{~mm}$ Tris-HCl, $\mathrm{pH} 8.8,1 \mathrm{~mm}$ EDTA, $10 \mathrm{~mm} 2$-mercaptoethanol, containing $2.5 \%$ (w/v) polyvinylpolypyrrolidone (PVPP) in a 1:2 ratio (sample fresh weight:buffer). After homogenization, samples were kept at $4^{\circ} \mathrm{C}$ for $1 \mathrm{~h}$ and then centrifuged at $23,500 \mathrm{xg}$ at $4^{\circ} \mathrm{C}$ for 15 $\mathrm{min}$. Aliquots of supernatant were desalted using a PD-10 column (GE Healthcare, Montreal, QB, and Canada). A $200 \mu \mathrm{L}$ aliquot of the PD-10 filtrate (or $200 \mu \mathrm{L}$ deionized water blank) was added to $400 \mu \mathrm{L}$ of reaction buffer (100 mM Tris$\mathrm{HCl}, \mathrm{pH} 8.5)$ and $200 \mu \mathrm{L}$ of substrate $(40 \mathrm{~mm} \mathrm{~L}-$ Phe, $100 \mathrm{mM}$ Tris-HCl, $\mathrm{pH} 8.8$ ) and incubated at $37^{\circ} \mathrm{C}$ for $15 \mathrm{~min}$. Trichloroacetic acid $(200 \mu \mathrm{L}$ of $25 \% \mathrm{w} / \mathrm{v}$ ) was added to terminate the reaction, and the samples were centrifuged at $13,000 \times \mathrm{xg}$ for 15 min. PAL activity was determined spectrophotometrically by measuring the increase in $\mathrm{A}_{290}$ due to the formation of trans-cinnamic acid. The level of PAL activity in each sample was measured using the regression curve from the trans cinamic acid standards $(0,20,40,60,80$, $100,120 \mathrm{~mm}$ ) and reported as IU/100 $\mathrm{mg}$ tissue. One unit of enzyme deaminated $1.0 \mu$ mole of Lphenylalanine to trans-cinnamate and ammonia per minute at $\mathrm{pH} 8.5$. 


\section{Statistical analyses}

Data analyses were done using the SPSS 14.0 software package (SPSS Inc., Chicago, IL, USA). All the experimental data were presented as the mean \pm SD. One-way ANOVA was used to test the differences between various means followed by post hoc Tukey test. The level of significance for all the tests was set at $\mathrm{P}<0.05$.

\section{RESULTS AND DISCUSSION}

\section{Molecular and phylogenic characteristics}

The SoPAL cDNA contained 2,118 nucleotides and an open reading frame encoding a protein with 706 amino acids and molecular weight of approximately $80 \mathrm{Kd}$. The full length cDNA of SoPAL was submitted to GenBank with an accession number of KC416026. There was no signal peptide at the N-terminus of cloned PAL.

Microbial and plant PAL enzymes are typically made up of four identical subunits. The molecular weight of the enzyme is approximately $330 \mathrm{kDa}$, with subunits ranging from $77-83 \mathrm{kDa}$ (Gilbert and Tully 1982). Like SoPAL, the most reported plant species such as Bambusa oldhamii, Hibiscus cannabinus, Nicotiana tabacum, Salvia miltiorrhiza have PAL with a similar number of amino acids 711-715 (Song and Wang 2009; Hsieh et al. 2010; Jeong et al. 2012). In comparison to SoPAL, some plant species such as Cucumis melon possess a shorter PAL protein with 619 amino acids while some plants have a longer PAL enzyme containing 721-745 amino acids such as Fagopyrum tataricum, Ginkgo biloba and Juglans regia (Diallinas and Kanellis 1994; Xu et al. 2008; Li et al. 2012; Xu et al, 2012;).

Based on the homology with other sequences in the GenBank, the following amino acids were identified in a conserved catalytic domain of SoPAL; Tyr 96, Glu 97, Val 98, Thr 100, Phe 102, Tyr 110, Gln 117, Leu 120, Pro 239, Lys 240, Glu 241, Glu 242, Leu 243, Asn 247, Tyr 338, Arg 341, Asp 371, and His 383 (Fig.1). This motif consisting of approximately 500 amino acids in the plant and fungal PAL with an amino acid sequence identity of $\geq 30 \%$ is common within this region among the different species (Pilbák et al. 2006).

The crystal structures of PAL showed that there was an inner lid loop and an outer lid loop located in close proximity to the active site of the enzyme. This inner loop was composed of amino acid residues spanning the region 102 through 124 of the protein sequence. Louie et al. (2006) have proposed that the function of this loop was in the substrate binding and catalysis. They have also reported that Tyr 110 and the amino acid residues within the active site of the enzyme were the most conserved residues in this family of enzymes. The analysis of the cDNA sequences of SoPAL by multiple sequence alignment tools indicated that it had been moderately conserved through the evolution. The SoPAL showed 96, 93, 87.12, $86.13,76.44$, and $75.66 \%$ homology with the PALs from Sorghum bicolor (sorghum) (AB565487.1), Zea mays (NM_001111864.1), Bambusa oldhamii (PAL4) (GU592807.1), Hordeum vulgare subsp. vulgare (Z49147.1), Bambusa oldhamii (PAL2) (FJ715635), and Oryza sativa Japonica Group (JQ065884.1), respectively. Results showed the deduced amino acid sequence of SoPAL had the highest similarity to the monocotyledonous species Oryza sativa Japonica, Zea mays, Sorghum bicolor in comparison to dicotyledenous species such as Arabidopsis thaliana.

Based on the structural similarity, the presence of the same prosthetic group and sequence conservation, it has been proposed that the genes encoding SoPAL and PAL from another species diverged from a common ancestral gene. To support this hypothesis, a phylogenetic tree was constructed based on the protein sequences of the PAL from different species of the plants, fungi, and bacteria as shown in Figure 2. The PAL homologues were supported by very strong bootstrap values. Deduced phylogenetic tree formed two different branches, first including the plant and another including the bacteria and fungi. PAL homologues from the plant species were grouped into three main sub-branches, including monocotyledonous, dicotyledenous and gymnosperm species. It was noticeable that $S$. officinarum was clustered with most well-known Geramineae species such as Oryza sativa, Zea mays and Sorghum bicolor. According to the traditional taxonomy, these species belonged to the same family, and the PAL gene of these plants cluster together meant that they shared higher similarity than other plants at the molecular level. 
atggogggcaacggogccatogtggagagogaccogetgaactggggogoggoggcagoggagctggoggggagccacctg $\begin{array}{lllllllllllllllllllllllllllll} & \mathbf{E} & \mathbf{A} & \mathbf{G} & \mathbf{N} & \mathbf{G} & \mathbf{A} & \mathbf{I} & \mathbf{V} & \mathbf{E} & \mathbf{S} & \mathbf{D} & \mathbf{P} & \mathbf{L} & \mathbf{N} & \mathbf{N} & \mathbf{G} & \mathbf{A} & \mathbf{A} & \mathbf{A} & \mathbf{A} & \mathbf{E} & \mathbf{L} & \mathbf{A} & \mathbf{G} & \mathbf{S} & \mathbf{H} & \mathbf{L}\end{array}$ gacgaggtgaagcgeatggtggogcaggccoggcagcoogtggtgaagatogagggctccacgetcogogtcggccaggtg

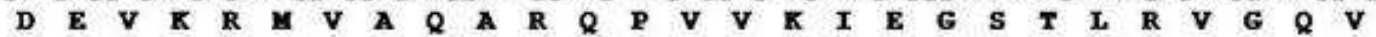
gcogeogtogeogcogccaaggacgegtogggegtogcogtogagetogacgaggaggecogcececgogtcaaggccagc $\begin{array}{llllllllllllllllllllllllllll}\mathbf{K} & \mathbf{D} & \mathbf{A} & \mathbf{S} & \mathbf{G} & \mathbf{V} & \mathbf{A} & \mathbf{V} & \mathbf{E} & \mathbf{L} & \mathbf{D} & \mathbf{E} & \mathbf{E} & \mathbf{A} & \mathbf{R} & \mathbf{P} & \mathbf{R} & \mathbf{V} & \mathbf{K} & \mathbf{A} & \mathbf{A} & \mathbf{A} & \mathbf{V} & \mathbf{A} & \mathbf{A} & \mathbf{A} & \mathbf{S}\end{array}$ agcgagtggatectogactgeatogeccacggoggegacatetacggogtcaccacoggettoggeggeacctcecacoge

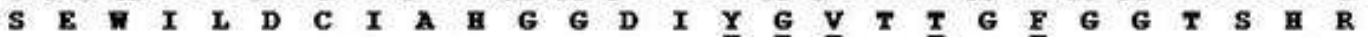
cgcaccaaggacgggecegctetccaggtogagctgctcaggcatctcaacgcoggaatettoggcacoggcagogatgge $\begin{array}{lllllllllllllllllllllllllll}\mathbf{R} & \mathbf{T} & \mathbf{K} & \mathbf{D} & \mathbf{G} & \mathbf{P} & \mathbf{A} & \mathbf{L} & \boldsymbol{Q} & \mathbf{V} & \mathbf{E} & \underline{\mathbf{L}} & \mathbf{L} & \mathbf{R} & \mathbf{H} & \mathbf{L} & \mathbf{N} & \mathbf{A} & \mathbf{G} & \mathbf{I} & \mathbf{F} & \mathbf{G} & \mathbf{T} & \mathbf{G} & \mathbf{S} & \mathbf{D} & \mathbf{G}\end{array}$ cacacgetgcogtoggaggtegtcogogoggegatgctggtgegcatcaacaccetcctccagogetactegggcatcecc

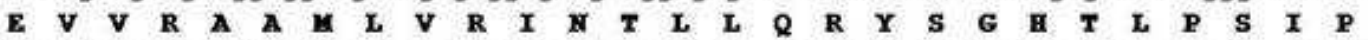
ttegagatcetggaggccatcaccaagetgctcaacaceggggtcagecogtgcetgecgetcoggggeaccatcacegog $\begin{array}{llllllllllllllllllllllllllll}\mathbf{F} & \mathbf{E} & \mathbf{I} & \mathbf{L} & \mathbf{E} & \mathbf{A} & \mathbf{I} & \mathbf{T} & \mathbf{K} & \mathbf{L} & \mathbf{L} & \mathbf{H} & \mathbf{T} & \mathbf{G} & \mathbf{V} & \mathbf{S} & \mathbf{P} & \mathbf{C} & \mathbf{L} & \mathbf{P} & \mathbf{L} & \mathbf{R} & \mathbf{G} & \mathbf{T} & \mathbf{I} & \mathbf{T} & \mathbf{A}\end{array}$ tegogogacetcotccogetctcetacatogcogeogcogaggogttcaagatogcoggeatogagggoggettcttcaag $\begin{array}{lllllllllllllllllllllllllllll}\mathbf{S} & \mathbf{R} & \mathbf{D} & \mathbf{L} & \mathbf{V} & \mathbf{P} & \mathbf{L} & \mathbf{S} & \mathbf{Y} & \mathbf{I} & \mathbf{A} & \mathbf{A} & \mathbf{A} & \mathbf{E} & \mathbf{A} & \mathbf{F} & \mathbf{K} & \mathbf{I} & \mathbf{A} & \mathbf{G} & \mathbf{I} & \mathbf{E} & \mathbf{G} & \mathbf{G} & \mathbf{F} & \mathbf{F} & \mathbf{K}\end{array}$ ctcaaccccaaggaaggtctogecategtgaacggetcetcegtgggetcogcectegoggccacegtgatgtacgacgec

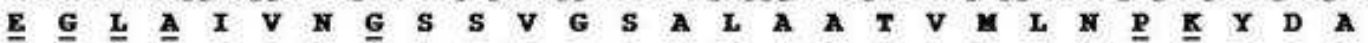
tacgtcctcaccgtcetgtcogaggtcetgtcogocgtcttgtgogaggtgatgaacogeatgocogagtacacogaccac $\begin{array}{llllllllllllllllllllllllllll}\mathbf{Y} & \mathbf{V} & \mathbf{L} & \mathbf{T} & \mathbf{V} & \mathbf{L} & \mathbf{S} & \mathbf{E} & \mathbf{V} & \mathbf{L} & \mathbf{S} & \mathbf{A} & \mathbf{V} & \mathbf{L} & \mathbf{C} & \mathbf{E} & \mathbf{V} & \mathbf{A} & \mathbf{N} & \mathbf{R} & \mathbf{M} & \mathbf{P} & \mathbf{E} & \mathbf{Y} & \mathbf{T} & \mathbf{D} & \mathbf{H}\end{array}$ ctcacccacaagctcaagcaccaccoggggtccatogaggecgcogccatcatggagcacatcetggacggcagogectte $\begin{array}{lllllllllllllllllllllllllll} & \mathbf{T} & \mathbf{H} & \mathbf{K} & \mathbf{L} & \mathbf{K} & \mathbf{H} & \mathbf{H} & \mathbf{P} & \mathbf{G} & \mathbf{S} & \mathbf{I} & \mathbf{E} & \mathbf{A} & \mathbf{A} & \mathbf{A} & \mathbf{I} & \mathbf{M} & \mathbf{E} & \mathbf{H} & \mathbf{I} & \mathbf{L} & \mathbf{D} & \mathbf{G} & \mathbf{S} & \mathbf{A} & \mathbf{F}\end{array}$ atgaagcacgccaagaaggtgaacgagctggaccogctgatcaagcccaagcaggacaggtacgogctcogcacgtcgcog $\begin{array}{lllllllllllllllllllllllllll}\mathbf{A} & \mathbf{K} & \mathbf{K} & \mathbf{V} & \mathbf{N} & \mathbf{E} & \mathbf{L} & \mathbf{D} & \mathbf{P} & \mathbf{L} & \mathbf{I} & \mathbf{K} & \mathbf{P} & \mathbf{K} & \boldsymbol{Q} & \mathbf{D} & \mathbf{R} & \underline{\mathbf{Y}} & \mathbf{A} & \mathbf{L} & \mathbf{A} & \mathbf{K} & \mathbf{H} & \underline{\mathbf{R}} & \mathbf{T} & \mathbf{S} & \mathbf{P}\end{array}$ cagtggctgggcocccagatogaggtcatoogogocgccaccaagtccatogagogogaggtcaactcogtcaacgacaac $\begin{array}{lllllllllllllllllllllllllll}\text { Q } & \mathbf{N} & \mathbf{L} & \mathbf{G} & \mathbf{P} & \mathbf{Q} & \mathbf{I} & \mathbf{E} & \mathbf{V} & \mathbf{I} & \mathbf{R} & \mathbf{A} & \mathbf{A} & \mathbf{T} & \mathbf{K} & \mathbf{S} & \mathbf{I} & \mathbf{E} & \mathbf{R} & \mathbf{E} & \mathbf{V} & \mathbf{N} & \mathbf{S} & \mathbf{V} & \mathbf{H} & \mathbf{D} & \mathbf{H}\end{array}$ coggtcatggacgtccacogtggcaaggogttgcacggoggcaacttccagggcacgcocatoggogtgtccatggacaac

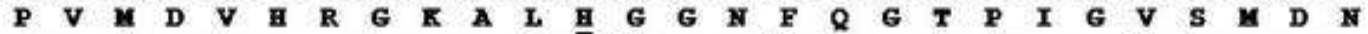
getogectogecatogccaacatoggcaagctcat'gttogegcagttctoggagetggtcaacgagttctacaacaacggg $\begin{array}{lllllllllllllllllllllllllllll}\mathbf{A} & \mathbf{R} & \mathbf{L} & \mathbf{A} & \mathbf{I} & \mathbf{A} & \mathbf{N} & \mathbf{I} & \mathbf{G} & \mathbf{K} & \mathbf{L} & \mathbf{H} & \mathbf{F} & \mathbf{A} & \boldsymbol{Q} & \mathbf{F} & \mathbf{S} & \mathbf{E} & \mathbf{L} & \mathbf{V} & \mathbf{A} & \mathbf{E} & \mathbf{F} & \boldsymbol{Y} & \mathbf{M} & \mathbf{N} & \mathbf{G}\end{array}$ ctcacctccaacctggcoggcagcogcaaccccagcetggactacggettgaagggcacggagaacgceatggcetcetac

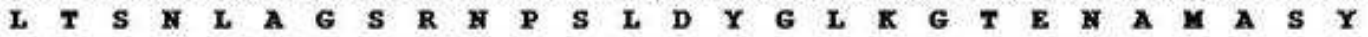
tgetctgagetgcagtacctgggcaaccccatcaccaaccacgtgcagagogoggagcagctcaaccaggacgtcaactce

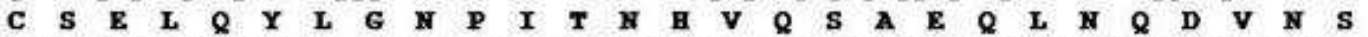
ttoggoctogtctcogccaggaagaccgocgaggccatogacatcotgaagctcatgtogtccacctacatogtggegctg

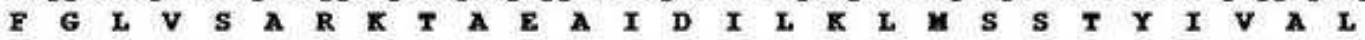
tgccaggccatogacctgcgecacctcgaggagaacatcaagacgtcoggtgaagaacagggtgacccaggtggogaagaag

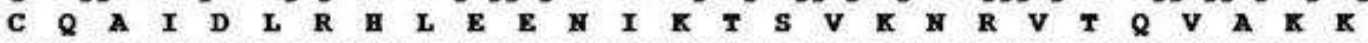
gtgetgaccatgaaccogtcaggogacctctccagogogogettcagogagaaggagctcatcaccgccategaccgagag

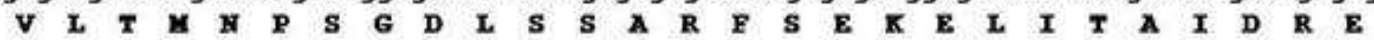
ggcgtgttcacctactoggaggacecggecagoggcagectgcogctgatgcagaagctgegetcogtgetggtggaccac

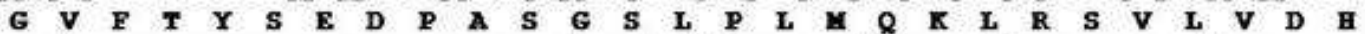
gccetcagcagoggogacgogggaacgggaccectcogtgttctccaagatcaccaaattogaggaggagctccacgoggg $\begin{array}{llllllllllllllllllllllllllll}\mathbf{A} & \mathbf{L} & \mathbf{S} & \mathbf{S} & \mathbf{G} & \mathbf{D} & \mathbf{A} & \mathbf{G} & \mathbf{T} & \mathbf{G} & \mathbf{P} & \mathbf{L} & \mathbf{R} & \mathbf{V} & \mathbf{L} & \boldsymbol{Q} & \mathbf{D} & \mathbf{H} & \boldsymbol{Q} & \mathbf{I} & \mathbf{R} & \mathbf{G} & \mathbf{G} & \mathbf{A} & \mathbf{P} & \mathbf{R} & \mathbf{G}\end{array}$ getggecogggaggtggaaggogeccegcttogccatgggecgagggcacogececogggogaaaccggaactgggacagc

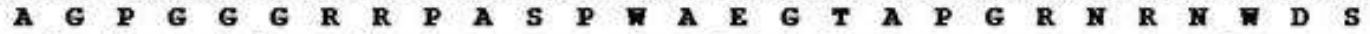
oggtogttcocogetgtacogettogtoogogaggagetoggetgtgtgttogtgacoggogagaagctcaaatcoccoggc

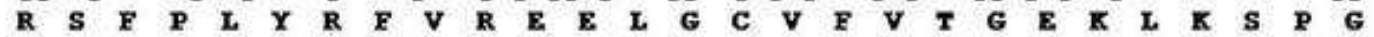
gaggagtgcagcaaggtgttcaacggcatcagccagggcaagctogtogaccecaagctogagtgectcaaggagtgggac

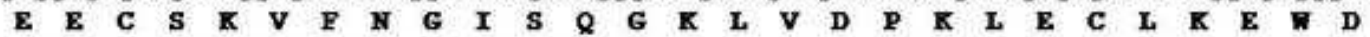
ggcaagcogetgcocatcaacgtogtcaactaa

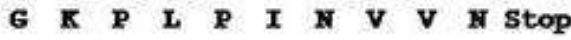

Figure 1 - The full length cDNA and deduced amino acids sequences of the SoPAL ortholog. The start codon (ATG), stop codon (TAA) and conserved catalytic site residues are underlined. 


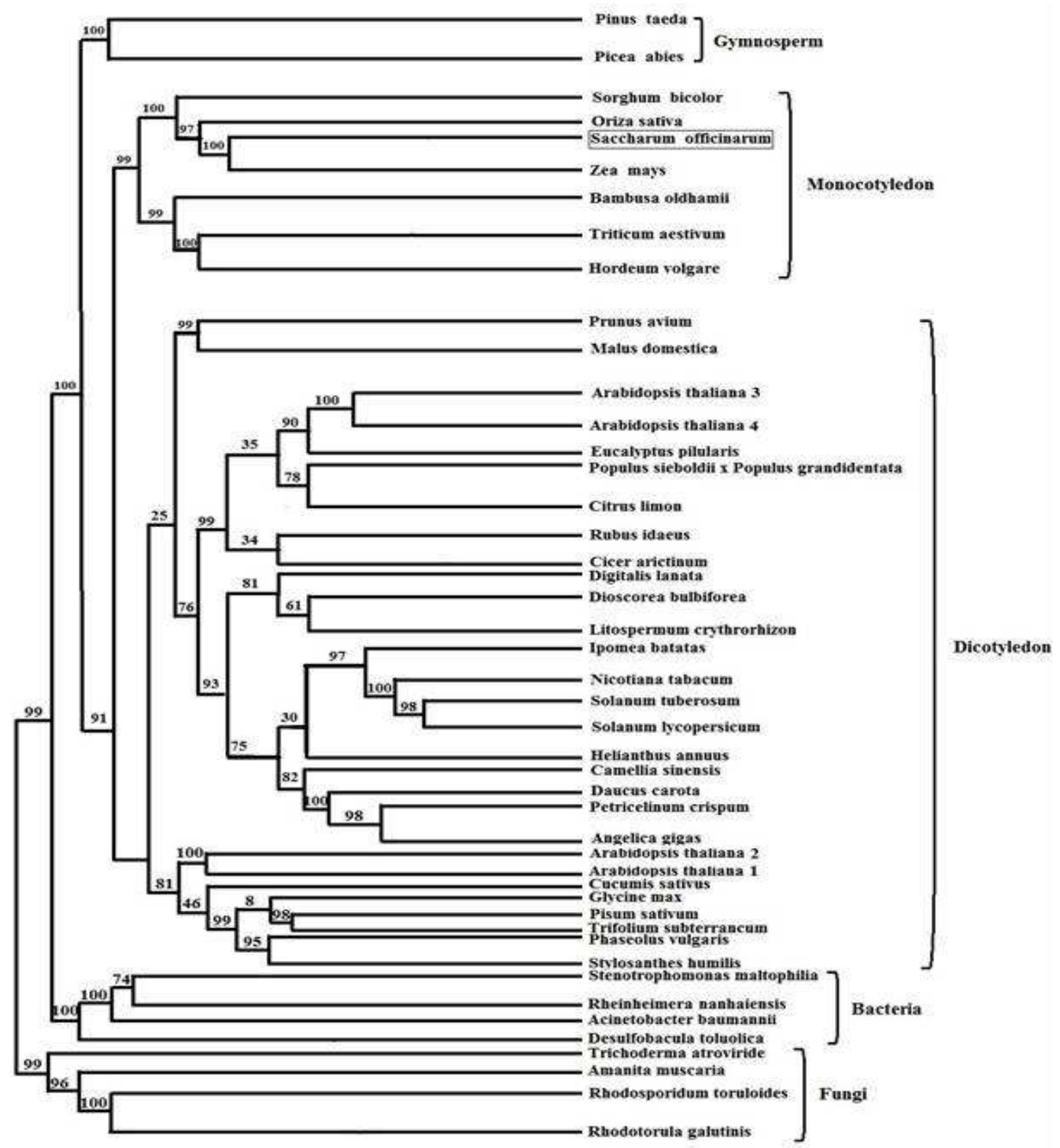

Figure 2 - Phylogenetic tree of SoPAL ortholog. The tree was generated using the neighbor joining method and Phylogeni.fr software based on homology between amino acid sequences of the SoPAL ortholog and PAL from other plants (gymnosperm, dicotyledonous and monocotyledonous), bacteria and fungi. The bootstrap values from 1000 replications are in percent at the nodes. The PAL sequences used were as follows: Pinus taeda (P52777), Picea abies (CAK22402), Sorghum bicolor (sorghum) (BAJ09365), Oryza sativa Japonica Group (P14717), Saccharum officinarum, Zea mays (NP_001105334), Bambusa oldhamii (PAL2) (FJ715635), Triticum aestivum (Q43210.1), Hordeum vulgare subsp. vulgare (CAA89007), Prunus avium (O64963.1), Malus $x$ domestica (P35512.1), Arabidopsis thaliana PAL3 (At5g04230), Arabidopsis thaliana PAL4 (At3g10340), Eucalyptus pilularis (AB591302.1), Populus trichocarpa x Populus deltoids (AAA33805), Citrus limon (Q42667), Rubus idaeus (Q9M568.1), Cicer arietinum (Q9SMK9.1), Digitalis lanata (O23924), Dioscorea bulbifera (BAA32233), Lithospermum erythrorhizon (O49835), Ipomoea batatas (Q42858), Nicotiana tabacum (P25872), Solanum tuberosum (P31425), Solanum lycopersicum ( AEW10551.1), Helianthus annuus (O04058.2), Camellia sinensis (P45726), Daucus carota (O23865.1), Petroselinum crispum (Q01861), Angelica gigas (AEA72280), Arabidopsis thaliana PAL1 (At2g37040), Arabidopsis thaliana PAL2 (At3g53260), Cucumis sativus (AER58180), Glycine max (P27991), Pisum sativum (Q01861), Trifolium subterraneum (P45734.1), Phaseolus vulgaris (P19142.1), Stylosanthes humilis (P45732.1), Stenotrophomonas maltophilia Ab55555 (EJP78738), Rheinheimera nanhaiensis E407-8 (ZP 09989772), Acinetobacter baumannii Ab44444 (EKB40550), Desulfobacula toluolica Tol2 (YP_006760683), Trichoderma atroviride IMI 206040 (EHK51094), Amanita muscaria (O93967), Rhodosporidium toruloides (CAA35886), Rhodotorula glutinis (ABB04148). 
Tissue expression and enzyme activity of SoPAL

The qRT-PCR was used to determine tissue expression of SoPAL gene during the tillering stage. As shown in Figure 3, SoPAL was expressed ubiquitously in the leaf, sheath, stem, and root. The highest relative abundance of SoPAL transcript was detected in the root and stem, respectively $(\mathrm{P}<0.05)$. The lowest level of expression was in the leaves and sheath, respectively $(\mathrm{P}<0.05)$ (Fig. 3). The expression of the PAL gene showed different patterns in various species.

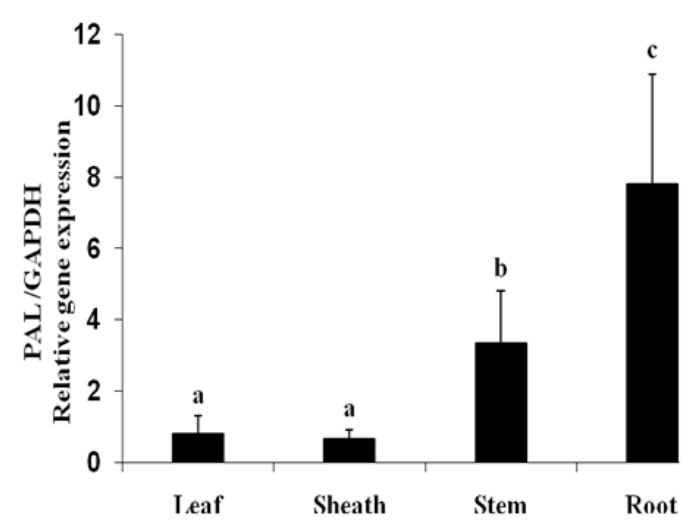

Figure 3 - Relative expression of SoPAL gene in different tissues during the tillering developmental stage. Expression values were normalized to those of GAPDH. Data were expressed as the mean fold difference (mean \pm SD). Values with different letters has significant difference $(\mathrm{P}>0.05)$.

PAL enzyme activity was assayed in the leaves, sheaths, stems, and roots of sugarcane throughout the tillering stage. As shown in Figure 4, there was a wide variation in the level of PAL activity in different tissues. The highest level of PAL activity was observed in the leaves and sheath, while the lowest PAL activity was detected in the root and stem $(\mathrm{p}<0.05)$.

Genes encoding PAL are expressed in a complex pattern during the plant development and in response to light, pathogen challenge, mechanical damage and other stresses (Huang et al. 2010). Differential expression of the PAL gene in different tissues of the sugarcane indicated that the rate of the phenylpropanoid synthesis pathway and the accumulated corresponding products might affect PAL expression. This hypothesis was supported by the fact that SoPAL gene was highly expressed in lignifying tissues such as stem. These results were in agreement with the findings of previous reports. High levels of the PAL transcripts were expressed in the root and flower of the tobacco plant (Nagai et al. 1994). Four transcripts of the Arabidopsis PAL genes have also been detected in inflorescent stem (Huang et al. 2010). Cochrane et al. (2004) reported that Arabidopsis PAL 1 and 2 expression patterns were very similar for various tissues such as callus, inflorescence, and roots.

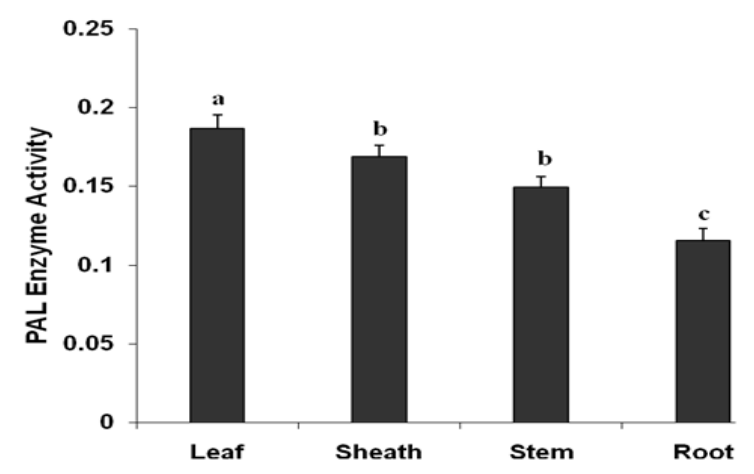

Figure 4 - Enzyme activity of PAL in different tissues of sugarcane during the tillering stage. Values with different letters indicate significant differences $(\mathrm{P}>0.05)$.

In spite of the higher expression of the PAL gene in sugarcane roots, only found minimal PAL enzyme activity was found in this tissue, while shoot and leaves with maximal enzyme activity had the lowest PAL gene expression. Although further studies would be necessary to respond this challenge, it might be due to regulation of PAL enzyme activity and gene expression by various environmental or plant specific regulatory factors, which acted at translational or posttranslational level (Turgeon et al. 2009). Some reports have demonstrated that different conditions of soil such as temperature and darkness have a regulatory role on PAL gene expression in the root (Yousefzadi et al. 2012). The inhibitory effects of red light on the expression of some key genes involved in the biosynthesis of phenylpropanoid metabolites, including the PAL gene have been shown by Yousefzadi et al. (2012). The induction of PAL and chalcone synthase expression has also been reported during the low temperature storage of the roots of Arabidopsis thaliana (Campos et al. 2003). Based on the above findings, it was concluded that high levels of PAL gene expression 
in sugarcane root could be related to the low temperature or light in the soil.

It is known that soil may contain different constituents, which affect directly the enzymatic reactions in the plant root. The effect of some ions and chemicals in the root exudates on the activity of PAL from different plant species has been demonstrated (Blanco et al. 2008). For example, allelochemicals, the predominant constituents identified in the root exudates, suppressed PAL activity and root growth in soybean (Herring and Lourdes 2002). Some compounds of the soil such as naringenin reduced the lignin content in gramineous plants, such as Zea mays, Oryza sativa and Echinochloa oryzicola by inhibiting the activity of the key enzyme of the phenylpropanoid pathway such as PAL (Bido et al. 2010). However, some discrepancies between the PAL mRNA level and its enzyme activity in root might be due to direct effect of environmental factors such as soli condition, density of light and temperature. Further studies would be necessary to confirm this hypothesis.

Although the regulatory mechanisms by which PAL is differentially controlled at transcriptional or functional levels remains unknown, it has been found that various biochemical and molecular effectors change the levels of enzyme transcription or activity. For example, recent evidence have indicated that mRNAs transport between different tissues, an important mechanism, which controlled the communication of signaling system in plants, could alter the abundance of mRNA and protein function independently (Turgeon et al. 2009). Another major reason, which might describe the difference between the PAL mRNA level and enzyme activity in some tissue could be the regulation of enzyme activity by allosteric regulators, which altered enzyme activity in spite of stable gene expression. It has been shown that trans cinamic acid, as product of PAL, lower or inhibits the PAL activity at high concentration (Chen et al. 2009). Trans cinamic acid is much more removed by the downstream pathways to synthesize other metabolites in higher growing tissues in this development stage such as leaves and its lower concentration of transcinamic acid in the leaves and sheaths might cause lower PAL enzyme activity in these tissue without any changes in abundance of its transcript.

\section{CONCLUSION}

PAL catalyzes the first step of the phenylpropanoid pathway, producing many metabolites, which play important functional roles in plant physiology and pathology. The application of these products has accelerated during the past decade due to their health and industrial benefits. Consequently, the characterization of PAL synthesis and its regulation at molecular level in many industrial plants such as sugarcane becomes essential. Such alteration of the phenylpropanoid composition in the plants is best achieved through the biotechnological processes.

This work characterized, for the first time, the molecular structure of the PAL gene from sugarcane and analyzed its expression pattern in different tissues. The phylogenetic tree analyses demonstrated that SoPAL has the best relationship to other monocotyledonous species such as sorghum, maize and bamboos. Sequence alignment of SoPAL amino acid sequences with PALs from other species showed the presence of a conserved catalytic motif. Results also showed differential expression of mRNA or enzyme activity of SoPAL in different tissues of the sugarcane, demonstrating the presence of different regulatory mechanisms at the transcriptional and functional level.

\section{ACKNOWLEDGMENTS}

This work was funded by a grant from the Ahvaz Jundishapour University of Medical Sciences (Project $\mathrm{N}^{\mathrm{o}}$ : CMRC-35), Shahid Chamran University of Ahvaz Research Council (Grant $\mathrm{N}^{\circ}: 636410,1391.4 .6$ and p.2.2186, 1392.10 .8 ). The authors declare that there is no conflict of interest.

\section{REFERENCES}

Bido GS, Lourdes M, Marchiosi R, Ferrarese-Filho O. Naringenin Inhibits the Growth and Stimulates the Lignification of Soybean Root. Braz Arch Biol Technol. 2010; 53(3): 533-542.

Blanco FA, Zanettim M E, Daleo RG. Calciumdependent Protein Kinases are involved in potato signal transduction in response to elicitors from the Oomycete Phytophthora infestans. J Phytopathology. 2008; 156: 53-61. 
Boller T. Chemoperception of microbial signals in plant cells. Annu Rev Plant Physiol Plant Mol Biol. 1995; 46: 189-214.

Campos AD, Ferreira AG, Vozari Hampe M, Antunes I, Branco N, Expedito P. Silveira EP et al. Induction of chalcone synthase and phenylalanine ammonia-lyase by salicylic acid and Colletotrichum lindemuthianum in common bean. Braz J Plant Physiol. 2003; 15(3): 129-134.

Campos-Vargas R, Nonogaki H, Suslow T, Saltveit M. Heat shock treatments delay the increase in wound induced phenylalanine ammonia-ammonia-lyase activity by altering its expression not its induction in Romaine lettuce (Lactuca sativa) tissue. Physiol Plantarum. 2005; 132: 82-91.

Chang A, Lim MH, Lee SW, Robb EJ, Nazar RN. Tomato Phenylalanine Ammonia-Lyase Gene Family, Highly Redundant but Strongly Underutilized. J Biol Chem. 2008; 283(48): 3359133601.

Chen MJ, Vijaykumar V, Lu BW, Xia B, Li N. Cis- and trans-cinnamic acids have different effects on the catalytic properties of Arabidopsis phenylalanine ammonia lyases PAL1, PAL2, and PAL4. J Integr Plant Biol. 2005; 47: 67-75.

Chiang VL, Puumala RJ, Takeuchi H, Eckert RE. Comparison of softwood and hardwood kraft pulping. Tappi. 1988; 71(9): 173-177.

Cochrane FC, Davin LB, Lewis NG. The Arabidopsis phenylalanine ammonia lyase gene family: kinetic characterization of the four PAL isoforms. Phytochemistry. 2004; 65(11): 1557-1564.

Copeland RA. Experimental measures of enzyme activity In Enzymes: A practical introduction to structure, mechanism and data analysis. Wiley Press, New York; 2000.

Coulon D, Faure L, Salmon M, Wattelet V, Bessoule JJ. $\mathrm{N}$-Acylethanolamines and related compounds: aspects of metabolism and functions. Plant Sci. 2012; 184: 129-140.

Diallinas G, Kanellis AK. A phenylalanine ammonialyase gene from melon fruit: cDNA cloning, sequence and expression in response to development and wounding. Plant Mol Biol. 1994; 26(1): 473-480.

Ferrer JL, Austin MB, Stewart C, Noelb JP. Structure and function of enzymes involved in the biosynthesis of phenylpropanoids. Plant Physiol Bioch. 2008; 46(3): 356-370.

Fukasawa Akada T, Kung SD, Watson JC. Phenylalanine ammonia-lyase gene structure, expression and evolution in Nicotiana. Plant Mol Biol. 1996; 30(4): 711-722.

Gao ZM, Wang XC, Peng ZH, Zheng B, Liu Q. Characterization and primary functional analysis of phenylalanine ammonia-lyase gene from Phyllostachys edulis. Plant Cell Rep. 2012; 31(7): 1345-56.
Gilbert HJ, Tully M. Synthesis and degradation of phenylalanine ammonia-lyase of Rhodosporidium toruloides. J Bacteriol. 1982; 150(2): 498-505.

Guillermo SH, Lopez MA, Hernandez D, Laura C, Miranda F, Rigua J, et al. Molecular cloning of cDNAs coding for three sugarcane enzymes involved in lignification. Plant Sci. 1999; 143: 163-171.

Herrig V, Ferrarese Mde L, Suzuki LS, Rodrigues JD, Ferrarese-Filho O. Peroxidase and phenylalanine ammonia-lyase activities, phenolic acid contents, and allelochemicals-inhibited root growth of soybean. Biol Res. 2002; 35(1): 53-61.

Hsieh LS, Yeh CS, Pan HC, Cheng CY, Yang CC, Lee $\mathrm{PD}$. Cloning and expression of a phenylalanine ammonia-lyase gene (BoPAL2) from Bambusa oldhamii in Escherichia coli and Pichia pastoris. Protein Expres Purif. 2010; 71(2): 224-230.

Huang J, Gu M, Lai Z, Fan B, Shi K, Zhou YH, et al. Functional analysis of the Arabidopsis PAL gene family in plant growth, development, and response to environmental stress. Plant Physiol. 2010; 153: 15261538.

Hyun MW, Yun YH, Kim JY, Kim SH. Fungal and Plant Phenylalanine Ammonia-lyase. Mycobiology. 2011; 39(4): 257-265.

Jeong MJ, Choi BS, Bae DW, Shin SC, Park SU, Lim $\mathrm{HS}$, et al. Differential expression of kenaf phenylalanine ammonia-lyase (PAL) ortholog during developmental stages and in response to abiotic stresses plants. Omics. 2012; 5(4): 392-400.

Jiang Y, Joyce DC. ABA effects on ethylene production, PAL activity, anthocyanin and phenolic contents of strawberry fruit. Plant Growth Regul. 2003; 39: 39-343.

Kleinhofs A, Haskins F A, Gorz H J. Relationship of Phenylalanine Ammonia-lyase Activity to $o$ Hydroxycinnamic Acid Content in Melilotus alba. Plant Physiol. 1966; 41(8): 1276-1279.

Lee BK, Park MR, Srinivas B, Chun JC, Kwon IS, Chung IM, Yoo NH, Choi KG, Yun SJ. Induction of Phenylalanine Ammonia-Lyase Gene Expression by Paraquat and Stress-related Hormones in Rehmannia glutinosa. Mol Cells. 2003; 16(1): 34-39.

Leng RA. Application of Biotechnology to nutrition of animals in developing countries in FAO animal production and health paper 90. Technical Papers. 1991; 120-145.

Li CL, Bai YC, Chen H, Zhao HX, Shao JR, Wu Q, Cloning. Characterization and functional analysis of a phenylalanine ammonia-lyase gene (FtPAL) from Fagopyrum tataricum Gaertn. Plant Mol Biol Rep. 2012; 30: 1172-1182.

Logemann PM, Parniske M, Hahlbrock K. Modes of expression and common structural features of the complete phenylalanine ammonia-lyase gene family in parsley. Proc Natl Acad Sci U.S.A. 1995; 92(13): 5905-5909. 
Louie GV, Bowman ME, Moffitt MC, Baiga TJ, Moore BS, Noel JP. Structural determinants and modulation of substrate specificity in phenylalanine-tyrosine ammonia-lyases. Chem Biol. 2006; 13(12): 1327-329.

Morelló JR, Romero MP, Ramo T, Motilva MJ. Evaluation of 1-phenylalanine ammonia-lyase activity and phenolic profile in olive drupe (Olea europaea L.) from fruit setting period to harvesting time. Plant Sci. 2005; 168(1): 65-72.

Nagai N, Kitauchi F, Shimosaka M, Okazaki M. Cloning and Sequencing of a Full-Length cDNA Coding for Phenylalanine Ammonia-Lyase from Tobacco Cell Culture. Plant Physiol. 1994; 104(3): 1091-1093.

Pilbák S, Tomin A, Rétey J, Poppe L. The essential tyrosine-containing loop conformation and the role of the C-terminal multi-helix region in eukaryotic phenylalanine ammonia-lyases. FEBS J. 2006; 273(5): 1004-1020.

Rieu I, Powers SJ. Real-time quantitative RT-PCR: design, calculations, and statistics. Plant Cell. 2009; 21(4): 1031-1033.

Schmittgen TD, Livak KJ. Analyzing real-time PCR data by the comparative CT method. Nat Protoc. 2008; 3(6): 1101-1108.

Shadle GL, Wesley SV, Korth KL, Chen F, Lamb C, Dixon RA. Phenylpropanoid compounds and disease resistance in transgenic tobacco with altered expression of 1-phenylalanine ammonia-lyase. Phytochemistry. 2003; 64: 153-162.

Song J, Wang Z. Molecular cloning, expression and characterization of a phenylalanine ammonia-lyase gene (SmPAL1) from Salvia miltiorrhiza. Mol Biol Rep. 2009; 36(5): 939-952.
Suresh I, Mattinson DS, Fellman JK. Study of the Early Events Leading to Cassava Root Postharvest Deterioration. Tropical Plant Biology. 2010; 3(3):151-165.

Turgeon R, Wolf S. Phloem transport: cellular pathways and molecular trafficking. Annu Rev Plant Biol. 2009; 60:207-21.

Wong W S, Guo D, Wang X L, Yin Z Q, Xia B, Li N. Study of cis-cinnamic acid in Arabidopsis thaliana. Plant Physiol Biochem. 2005; 43: 929-937.

$\mathrm{Xu} \mathrm{F}$, Cia R, Cheng S, Du H, Wang Y, Cheng S. Molecular cloning, characterization and expression of phenylalanine ammonia-lyase gene from Ginkgo biloba. Afr J Biotechnol. 2008; 7 (6): 721-729

Xu F, Deng G, Cheng S, Zhang W, Huang X, Li L, Cheng H, Rong X, Li J. Molecular cloning, characterization and expression of the phenylalanine ammonia-lyase gene from Juglans regia. Molecules. 2012; 17(7): 7810-7823.

Yang HR, Tang M, Liu K, Huanh J. Effect of salicylic acid on jasmonic acid-related defense response of pea seedlings to wounding. Sci Horti Amsterdam. 2011; 128(3): 166-173.

Yousefzadi M, Sharifi M, Behmanesh M, Ghasempour A, Moyano E, Palazon J. The effect of light on gene expression and podophyllotoxin biosynthesis in Linum album cell culture. Plant Physiol Biochem. 2012; 56: 41-46. 